\title{
Influências nutricionais na psoríase *
}

\author{
Nutritional influences in psoriasis
}

Maria Lúcia Diniz Araujo ${ }^{1}$

\author{
Maria Goretti P. de A. Burgos ${ }^{2}$
}

Isis Suruagy Correia Moura ${ }^{3}$

\begin{abstract}
Resumo: A psoríase é uma doença inflamatória de pele, mediada por células T, hereditária, que sofre influência ambiental. Ingestão elevada de ômega-3, jejum, dietas hipocalóricas e vegetarianas mostram efeitos benéficos. Alguns pacientes que apresentam anticorpos antigliadina IgA/IgG, com sensibilidade ao glúten, melhoram após a retirada deste. O calcitriol é usado no tratamento tópico. Ingestão de álcool pode exacerbar a doença. Neste trabalho, analisam-se fatores dietéticos e descrevem-se seus benefícios na psoríase.

Palavras-chave: Ácidos graxos ômega-3; Antioxidantes; Bebidas alcoólicas; Dieta; Glúten; Psoríase

Abstract: Psoriasis is an inherited inflammatory skin disease mediated by T-cells and influenced by environmental factors. High intake of omega-3, fasting, low-calorie and vegetarian diets show beneficial effects. Some patients presenting IgA/IgG antigliadin antibodies and who are gluten-sensitive improve after a gluten-free diet. Calcitriol is used in topical treatment. The use of alcohol may exacerbate the disease. In this report, diet factors are analyzed and their benefits in psoriasis are described.

Keywords: Alcoholic beverages; Antioxidants; Diet; Fatty acids, omega-3; Gluten; Psoriasis
\end{abstract}

\section{INTRODUÇÃO}

A psoríase é doença inflamatória crônica da pele, mediada por células T, caracterizada por lesões eritematoescamosas, aumento na proliferação celular e padrões anormais de diferenciação dos queratinócitos ${ }^{1,2}$. Apresenta prevalência mundial estimada em $2 \%^{1,3}$, variando entre $0,6 \%$ e $4,8 \%$, sem predileção por sexo nem por faixa etária, sendo mais comum entre a terceira e a quarta décadas, no sexo feminino e em indivíduos com história familiar ${ }^{4,5}$.

As causas são desconhecidas, porém uma predisposição genética ${ }^{3}$, associada a fatores ambientais como fumo, álcool, alimentação, infecção, drogas e eventos estressantes, constitui uma explicação etiológica plausível ${ }^{3}$.

A prevalência e a gravidade da psoríase têm se mostrado diminuídas durante períodos de jejum. Dietas hipocalóricas levam à melhora dos sintomas ${ }^{2}$ e podem ser importantes fatores adjuvantes na prevenção e no tratamento do tipo não-pustular moderado ${ }^{4}$.

Apesar de vários mecanismos serem discutidos, a causa direta desses efeitos positivos nos sintomas da doença ainda é desconhecida ${ }^{2}$. A explicação mais importante é, provavelmente, a diminuição na ingestão do ácido araquidônico (AA), que resulta na menor produção de eicosanoides inflamatórios. Durante o jejum, ocorre redução na ativação das células TCD4 e elevação no número e/ou na função da interleucina 4 (citocina anti-inflamatória) 1 e a restrição calórica leva à redução do estresse oxidativo ${ }^{1}$.

\footnotetext{
Aprovado pelo Conselho Editorial e aceito para publicação em 22.12.08.

* Trabalho realizado no Serviço de Nutrição do Hospital das Clinicas (UFPE) - Recife (PE), Brasil.

Conflito de interesse: Nenhum / Conflict of interest: None

Suporte financeiro: Nenhum / Financial funding: None

Mestranda em Nutrição pela Universidade Federal de Pernambuco (UFPE). Especialista em Nutrição Clínica pela Universidade Federal de Pernambuco (UFPE) - Recife (PE), Brasil.

Doutora em Nutrição. Especialista em Terapia Nutricional Enteral e Parenteral pela Sociedade Brasileira de Nutrição Parenteral e Enteral (SBNPE). Especialista em Nutrição Clínica pela Associação Brasileira de Nutrição (Asbran). Nutricionista da Clínica de Dermatologia do Hospital das Clínicas da Universidade Federal de Pernambuco (HCUFPE). Nutricionista pesquisadora da Universidade Federal de Pernambuco (UFPE) - Recife (PE), Brasil.

Nutricionista residente da Clínica de Dermatologia do Hospital das Clínicas da Universidade Federal de Pernambuco (HCUFPE) - Recife (PE), Brasil
} 
Dietas vegetarianas podem ser benéficas em todos os pacientes com psoríase, visto que há ingestão diminuída de $\mathrm{AA}$ e conseqüente redução na formação de eicosanoides inflamatórios. Concentrações elevadas de AA e de seus metabólitos pró-inflamatórios foram observadas em lesões psoriáticas, assim como em outras desordens autoimunes e inflamatórias. Uma opção terapêutica na psoríase é a substituição do AA por um ácido graxo (AG) alternativo, especialmente o eicosapentaenoico (EPA), que pode ser metabolizado pelas mesmas vias enzimáticas do $\mathrm{AA}^{2,5}$.

Quanto ao efeito da suplementação oral de ômega-3 nessa enfermidade, os resultados são conflitantes e não são claros em relação à dose a ser utilizada5. A maioria das pesquisas apresenta efeitos positivos; entretanto, resultados de testes randomizados e controlados são menos efetivos ${ }^{2}$. Apesar dos resultados ainda inconsistentes, pode-se recomendar ingestão de peixes ricos em ômega-3. Em pacientes com psoríase agudizada, infusões parenterais de ômega-3 podem ser benéficas ${ }^{2}$.

Estudos recentes evidenciaram uma associação entre a doença celíaca (DC) e a psoríase6; todavia, tal relação ainda é bastante controversa, uma vez que os dados são escassos6. Quanto à dieta isenta de glúten, sabe-se que poderá melhorar as lesões de pele, mesmo em pacientes sem DC, mas com anticorpos antigliadina IgA e $\operatorname{IgG}^{7}$. Dados da literatura ainda são escassos na explicação dos mecanismos envolvidos na associação entre DC, psoríase e dieta isenta de glúten nas lesões de pele. Várias hipóteses têm sido propostas, como alteração na permeabilidade intestinal, mecanismos imunes e deficiência de vitamina $\mathrm{D}^{6}$.

Estresse oxidativo e formação elevada de radicais livres têm sido relacionados à inflamação da pele na psoríase $^{2}$. Estudos mostram que indivíduos com essa doença apresentam concentrações elevadas de malonilaldeído, um marcador da peroxidação lipídica, e estado antioxidante prejudicado, com níveis diminuídos de $\beta$-caroteno, $\alpha$-tocoferol e selênio ${ }^{7}$.
O selênio apresenta propriedades imunomodulatórias e antiproliferativas. A literatura indica que pacientes com desordens inflamatórias de pele, melanoma maligno e linfoma cutâneo de células T apresentam baixas concentrações desse elemento ${ }^{8}$. Seu baixo nível pode ser fator de risco para o desenvolvimento da psoríase, sendo poucos os trabalhos publicados ${ }^{7}$. Níveis diminuídos de selênio relacionam-se com a gravidade da doença e podem ocorrer devido à baixa ingestão alimentar ou à excessiva descamação da pele ${ }^{8}$.

Dentre outros fatores que podem elevar o estresse oxidativo e reduzir os antioxidantes naturais, em indivíduos com história da doença há mais de três anos, relata-se a ingestão alcoólica elevada e o fumo ativo e/ou passivo8. Homens jovens e de meia-idade apresentam riscos com ingestão de álcool enquanto que, em mulheres, não é fator de risco, mas agrava o quadro clínico ${ }^{9}$. Pacientes psoriáticos devem evitar a ingestão de álcool, principalmente, nos períodos de exacerbação, quando ocorre elevado risco de cirrose hepática associado com metotrexato ou outros tratamentos hepatotóxicos ${ }^{2}$.

O calcitriol e seus análogos exercem efeitos antiproliferativos e pró-diferenciativos, o que justifica a sua importância na psoríase. Deve-se considerar suplementação oral da vitamina $\mathrm{D}$ em pacientes com psoríase que não fazem o tratamento tópico com a vitamina ${ }^{2,10}$.

Finalmente, pode-se dizer que a dieta é fator importante na patogênese da psoríase e que, apesar de os resultados da literatura com suplementação oral de óleo de peixe serem inconsistentes, os pacientes podem ser orientados a ingerir peixes ricos em ômega-3, por seus benefícios no quadro clínico. A pacientes hospitalizados com doença aguda sugerem-se infusões parenterais de ácido graxo poli-insaturado. Outros estudos devem ser realizados para esclarecer o papel da dieta isenta de glúten, o que pode diminuir a gravidade da doença em pacientes com anticorpos. A vitamina D tem sido uma opção terapêutica, devido a suas atividades imunorregulatórias e antiproliferativas. 


\section{REFERÊNCIAS}

1. Ghoreschi K, Mrowietz U, Rocken M. A molecule solves psoriasis? Systemic therapies for psoriasis inducing inter leukin 4 and Th2 responses. J Mol Med. 2003;81:471-80.

2. Wolters M. Diet and psoriasis: experimental clinical and evidence. Br J Dermatol. 2005;153:706-14.

3. Naldi L. Epidemiology of psoriasis. Curr Drug Targets Inflamm Allergy. 2004;3:121-8.

4. Ruceviæ I, Perl A, Barisiæ-Drusko V, Adam-Perl $M$. The role of low energy diet in psoriasis vulgaris treat ment. Coll Antropol. 2003;Suppl. 1:41-8.

5. Mayser P, Grinn H, Gringer F. Omega-3 fatty acids in psori asis. Br J Nutrition. 2002;87(Suppl 1):S77-82.

6. Woo WK, McMillan SA, Watson RG, McCluggage WG, Sloan JN, McMillan JC. Coeliac disease - associated antibodies correlate with psoriasis activity. $\mathrm{Br} \mathrm{J}$ Dermatol. 2004;151:891-4.

7. Briganti S, Picardo M. Antioxidant activity, lipid peroxida tion and skin disease. What's new. J Eur Acad Dermatol Venearol. 2003;17:663-9.
8. Serwin $\mathrm{AB}$, Wasowicz $\mathrm{W}$, Gromadzinska J, Chodynicka B. Selenium status in psoriasis and its relation to the durat ion and severity of the disease. Nutrition. 2003;19:301-4.

9. Poikolainen K, Reunala T, Karvonen J, Lauharanta J, Karkkainen P. Alcohol intake: A risk factor for psoriasis in oung and midlle aged men? BMJ. 1990;300:780-3.

10. Holick MF. Vitamin D: a millennium perspective. J Cell Biochem. 2003;88:296-307.

ENDEREÇO PARA CORRESPONDÊNCIA / MAILING ADDRESS:

Maria Goretti P. de A. Burgos

Depto. Clínica Médica da Fac. Medicina da UFMG

Rua Baltazar Pereira, 70/601 - Boa Viagem

51011550 - Recife - PE

Tel.: (81) 3325-3873

E-mail: gburgos@botlink.com.br 